\title{
Influences of characteristic meteorological conditions on atmospheric carbonyls in Beijing, China
}

\author{
Xiaobing Pang ${ }^{\mathrm{a}, \mathrm{b}, *}$, Yujing $\mathrm{Mu}^{\mathrm{b}}$, Xinqing Lee ${ }^{\mathrm{a}}$, Yujie Zhang ${ }^{\mathrm{b}}$, Zhu Xu ${ }^{\mathrm{b}}$ \\ a State Key Laboratory of Environmental Geochemistry, Institute of Geochemistry, CAS, Guiyang 550002, China \\ ${ }^{\mathrm{b}}$ Research Center for Eco-environmental of Sciences, CAS, Beijing 100085, China
}

\section{A R T I C L E I N F O}

\section{Article history:}

Received 7 December 2008

Received in revised form 5 May 2009

Accepted 5 May 2009

\section{Keywords:}

Beijing

Carbonyls

Dust storm

Meteorological conditions

\begin{abstract}
A B S T R A C T
Atmospheric pollutants are controlled not only by their production rates but also by meteorological conditions. The influences of dust storm, sauna weather (haze with high temperature and high humidity), wet precipitation and wind speed on atmospheric carbonyls in Beijing were investigated. During a severe dust episode (April 17, 2006), the mixing ratios of carbonyls were significantly elevated to $13-27 \mathrm{ppbV}$ from 7 to $13 \mathrm{ppbV}$ in the previous non-dust days (April 15 and 16) with the increasing extents of 38-154\%. The accumulating effect and the lower photolysis rate in the dust day may be responsible for the increases of carbonyls' levels. Additionally, the contribution from heterogeneous reactions occurring on dust particles to formaldehyde and acetaldehyde cannot be ruled out. During the period of typical sauna weather, the concentrations of atmospheric carbonyls increased to 18-60 ppbV from 10 to 17 ppbV before the sauna days. The air mass over Beijing during the sauna days was controlled by a subtropical anticyclone and the boundary layer became quite stable, which was beneficial to the rapid accumulation of air pollutants including carbonyls. Wet precipitation was found to be an effective removal process to the atmospheric carbonyls. After one-hour of rain in summer, the total concentrations of atmospheric carbonyls decreased to less than half of that before the rainfall. The similar temporal varying patterns of carbonyls and inorganic ions in rainwater indicated that carbonyls were mainly washed out from the atmosphere into rainwater as inorganic ions were. Strong wind could evidently dilute atmospheric carbonyls and a negative correlation was found between wind speeds and the concentrations of carbonyls in spring in Beijing.
\end{abstract}

(c) 2009 Elsevier B.V. All rights reserved.

\section{Introduction}

Meteorological conditions such as dust storm, sauna weather (haze with high temperature and high humidity), wet precipitation, wind velocity, relative humidity $(\mathrm{RH})$, barometric pressure, and mixing layer height (MLH) etc., can significantly affect atmospheric pollutants by several physical processes, namely, the dispersion, the transformation and the removal of air pollutants. In many studies, the meteorological conditions have been recognized as the important factors controlling the levels of some regular air

* Corresponding author. State Key Laboratory of Environmental Geochemistry, Institute of Geochemistry, CAS, Guiyang 550002, China.

E-mail address: pangxiaobing@mails.gyig.ac.cn (X. Pang). pollutants such as ozone, $\mathrm{NO}_{X}, \mathrm{SO}_{2}, \mathrm{CO}_{2}$, and particulate matter $\left(\mathrm{PM}_{10}, \mathrm{PM}_{2.5}, \mathrm{PM}_{1}\right)$, etc. (Sezer et al., 2005; Pudasainee et al., 2006; Seto and Hara, 2006; Alves, 2008; Pateraki et al., 2008). In Sao Paulo in Brazil, the increased MLH and the enhanced wind speeds could promote the dilution of surface ozone and resulted in the decrease of ozone levels (SachezCcoyllo et al., 2006). The ozone levels during the premonsoon were observed to be significantly higher than the values during the monsoon in Thailand and Nepal (Zhang and Kim Oanh, 2002; Pudasainee et al., 2006). During the premonsoon, the metrological conditions of high air temperature, strong solar radiation and lack of rainfall could give rise to the accumulation of ground-level ozone. In Erzurum of Turkey, high levels of TSP and $\mathrm{SO}_{2}$ were often found in the days with the weather conditions of low temperature, low 
wind speed, low wet precipitation, high barometric pressure, and high relative humidity (Sezer et al., 2005). In Pearl River Delta of China and Utah's Cache Valley of USA, the time of a series of serious PM 2.5 events coincided with the period of strong temperature inversion in winter and fall (Fan et al., 2008; Silva et al., 2007), while in New York, the events of serious $\mathrm{PM}_{2.5}$ pollution usually occurred in the summer days with high temperature and high humidity (DeGaetano and Doherty, 2004). The unfavorable meteorological conditions in any seasons would all result in the high levels of air pollutants. To our knowledge, however, there were few literatures focusing on the influences of meteorological conditions on atmospheric VOCs, especially carbonyls. Carbonyls play a crucial role in the formation of photochemical smog and secondary organic aerosol (SOA) because the free radicals produced from the photolysis of carbonyls can react rapidly with $\mathrm{OH}$ radical and serve as the precursors of ozone (Finlayson-Pitts and Pitts, 1997). In metropolitan air, carbonyls are primarily emitted by mobile vehicles and stationary sources and secondarily produced by the photo-oxidation of their precursors (Grosjean et al., 2002). Any meteorological variations affecting the atmospheric conditions will influence the atmospheric carbonyls and accordingly change the levels of ozone and aerosol. Up to now, few researches have been performed on this issue except for the several studies discussing wet precipitation as a removal process for atmospheric carbonyls (Zhou and Mopper, 1993; Matsunaga et al., 2007; Mu et al., 2007).

In the present article, the major goal is to clarify the effects of dust storm, sauna weather, wet precipitation and wind speed on the levels of atmospheric carbonyls in Beijing and to describe the variations of atmospheric carbonyls.

\section{Experimental}

\subsection{Site description}

Beijing City (39.81 N, 116.51E), the capital city of China, is located at temperate zone with half-moist continent monsoon climate. It is relatively windy, sand stormy and dry in spring (March, April and May). It is hot, humid and abundant with wet precipitation in summer (June, July and August). In July and August, the haze weather with high RH and high air temperature often occurs in Beijing. This type of characteristic weather is defined as sauna weather. It is usually clear and warm in autumn (September and October). Winter (from November to February) is quite cold and dry. Mean monthly air temperature ranged from $-4.3{ }^{\circ} \mathrm{C}$ in January to $25.9{ }^{\circ} \mathrm{C}$ in July of 2006 (http://www.cma.gov.cn). Field sampling was conducted on a rooftop (about $15 \mathrm{~m}$ above ground) in the Research Center for Eco-Environmental Sciences (RCEES), Chinese Academy of Sciences. The surroundings of RCEES are several institutes, campuses, residential apartments, and two side roads with moderate traffic. No industrial emissions of carbonyls were found near this sampling site.

\subsection{Carbonyls sampling and analysis}

The sampling processes and the analysis procedures of atmospheric carbonyls in gaseous phase were mainly based on the EPA TO-11A method (EPA, 1999). Ambient air was drawn through a 2, 4-dinitrophenylhydrazine (DNPH)-coated silica gel cartridge (Waters, United States) by a mini-pump (KNF Neuberger, Germany). A Teflon filter and a KI scrubber were consecutively connected to the inlet of the DNPH-coated cartridge to remove particulate matter and eliminate the interference from ozone, respectively. Gaseous carbonyls can rapidly react with DNPH and chemically transform into their corresponding hydrazones. The carbonyls' hydrazones were separated by a Thermo ODS Hypersil column (5 $\mu \mathrm{m}$, $250 \times 5.0 \mathrm{~mm}$ ) and automatically analyzed by an UV/Vis detector in an Alliance 2695 HPLC system (Waters, USA).

Rain sampling was conducted from August 15 to 16, 2005 and seven rainwater samples were collected. An aliquot $(10.0 \mathrm{ml})$ of each rainwater sample just after collection was immediately mixed with DNPH solution. The carbonyls in rainwater were derived into their respective hydrazones and subsequently analyzed by HPLC. Inorganic ions in the rainwater samples were determined by a Diononex DX-120 ion chromatography. The measurement of ozone, photosynthetically active radiation (PAR) and meteorological parameters (relative humidity, air temperature, and wind speed/direction) were made using standard instruments located on the same rooftop.

\section{Results and discussion}

During the sampling period, nine carbonyls were identified in Beijing ambient air. Among those carbonyls, formaldehyde, acetaldehyde, acetone, propionaldehyde and benzaldehyde were found as the principal species. Formaldehyde was observed as the predominant specie in the most samples. Therefore, the five carbonyls will be primarily discussed in the following sections.

\subsection{Influences of dust storm on atmospheric carbonyls}

From the night of April 16 to April 18, 2006, the strongest dust storm among those recorded in the past five years attacked Beijing with a dust fall of 10 tons $/ \mathrm{km}^{2}$. The temporal variations of atmospheric carbonyls and meteorological parameters during April 15-17 and April 19, 2006 are shown in Fig. 1. During the non-dust days (April15 and 16), higher levels of atmospheric carbonyls were observed in the morning rush hours and early afternoon, indicating the local vehicular emissions during the morning rush hours and the photo-oxidation at noon make important contributions to atmospheric carbonyls.

On the dust day (April 17), the mixing ratios of carbonyls were significantly elevated to $13-27 \mathrm{ppbV}$ from 7 to $13 \mathrm{ppbV}$ on the non-dust days (April 15 and 16) with the increasing extents of $38-154 \%$. The amounts of carbonyls emitted from major direct sources (vehicular exhaust and domestic emission) near the monitoring site may be basically equal between the dust day and the non-dust day. The relatively lower PAR intensities and the lower ozone levels on the dust day implied that the contribution from photo-oxidation to carbonyls may be less on the dust day than that on the non-days. Therefore, the direct emissions and the photochemical production may not be the exact reasons for the increases of carbonyls' levels. It was reported that a stable inversion layer was observed to be concurrently formed over Beijing on April 16 (Sun et al., 

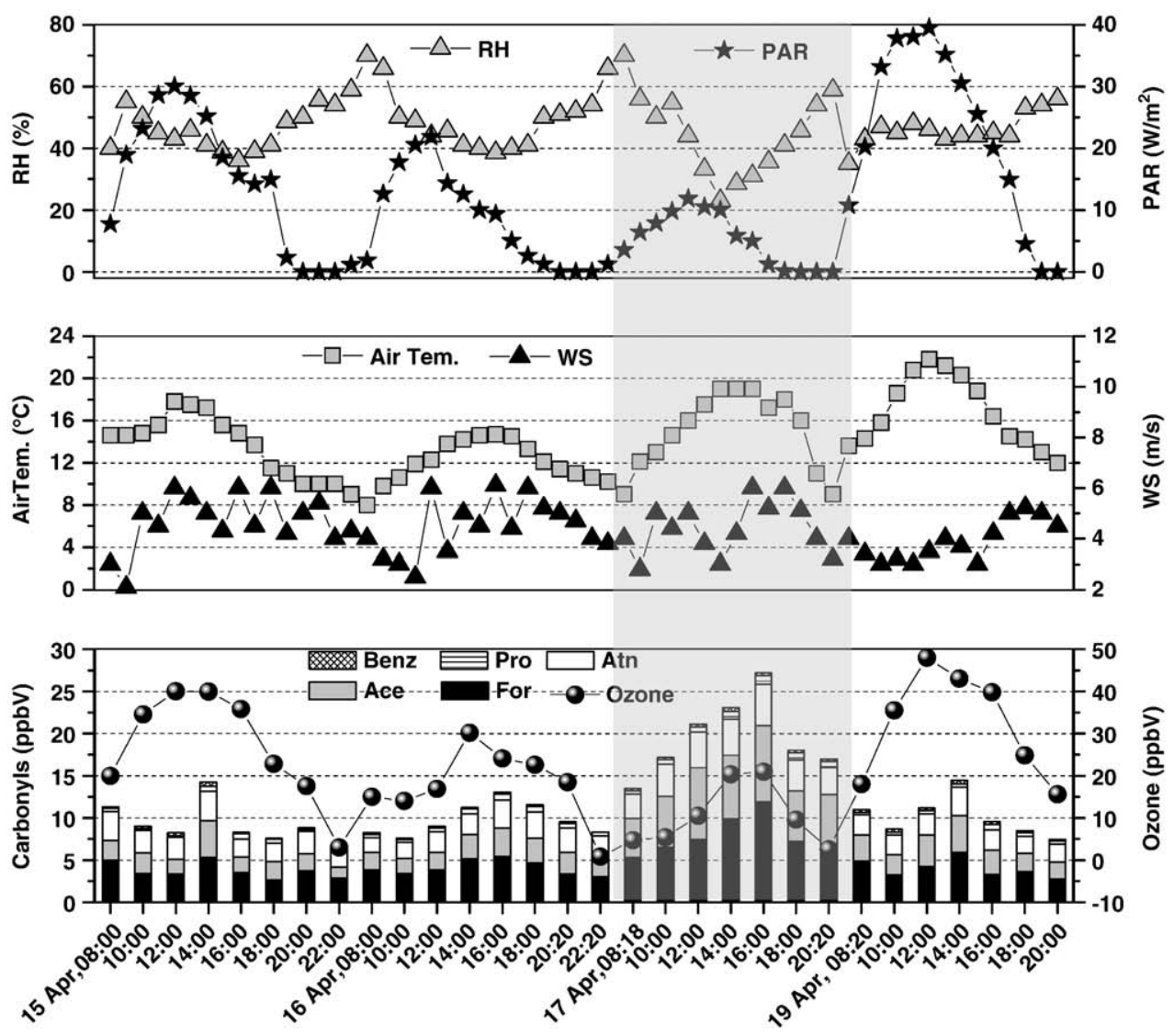

Sampling Time (LT)

Fig. 1. Temporal variations of atmospheric carbonyls and meteorological parameters during the period of the dust storm (April 15-17 and April 19, 2006). The period of dust storm is presented as the gray area. For, Ace, Can, Pro, RH, PAR and WS indicate formaldehyde, acetaldehyde, acetone, and propionaldehyde, relative humidity, photosynthetically active radiation and wind speed, respectively.

2007) as the dust storm arrived. The MLH decreased from 1079 m on April 15 to 826 m on April 17 (http://www.cma. gov.cn). Under such meteorological conditions, atmospheric carbonyls would rapidly accumulate and result in the increases of carbonyls' levels on the dust day. The accumulations of $\mathrm{PM}_{10}, \mathrm{SO}_{2}, \mathrm{NO}_{X}$ and $\mathrm{O}_{3}$ were also observed during the previous dust storms in Beijing (Guo et al., 2004; Xie et al., 2005). Recently, more organic compounds e.g. alcohols, saccharides, and fatty acids etc. were found on the dust particulates during the dust episode than on the normal aerosols during non-dust days (Wang et al., 2009). Some of those organic compounds can volatilize from dust particles and may subsequently be photo-oxidized to carbonyls.

On the dust day, the average increasing percentages of formaldehyde, acetaldehyde, acetone, propionaldehyde and benzaldehyde were 97.6\%, 181.8\%, 45.6\%, 59.9\% and $42.1 \%$, respectively. Since propionaldehyde and benzaldehyde were mainly emitted from anthropogenic sources in city ambient air (Anderson et al., 1996), the increases of their concentrations may mainly be ascribed to the accumulating effect on the dust day. Acetone is an inactive carbonyl in the atmosphere and the increase of its level may also be due to the accumulation. The higher increases of formaldehyde and acetaldehyde levels implied that other reasons may also be responsible for their enhancements except for the accumulating effect. In the atmosphere, major loss processes for formaldehyde and acetaldehyde were photolysis and $\mathrm{OH}$-induced photo-degradation. The lifetimes were calculated to be $4 \mathrm{~h}$ for formaldehyde and $8.8 \mathrm{~h}$ for acetaldehyde in the simulated troposphere (Atkinson, 2000). The lower PAR intensities and lower ozone levels on the dust day would decrease the rates of photolysis and photo-degradation of the two species (Possanzini et al., 2002), which may result in their higher increases. On the dust day, the TSP concentrations in Beijing ambient air were extremely high with the average of $1200 \mu \mathrm{g} \mathrm{m}{ }^{-3}$, which were 5-10 times higher than those on the non-dust days, and the diameters of dust particulates were lower than $74 \mu \mathrm{m}$ (Han et al., 2007). The abundant fine dust particulates would be conductive to those heterogeneous reactions occurring on their large surface in the troposphere (Jacob, 2000; Andreae and Crutzen, 1997). It was proved that alkene, olefinic and aliphatic compounds could be oxidized to formaldehyde and acetaldehyde through the heterogeneous reactions (Thomas et al., 2001; Salisbury et al., 2006). Therefore, the contribution from heterogeneous reactions to the two species cannot be ruled out in this study. It should be noted that the levels of atmospheric carbonyls in April 19 became as low as those before the dust episode. The reason for this phenomenon may be that some 

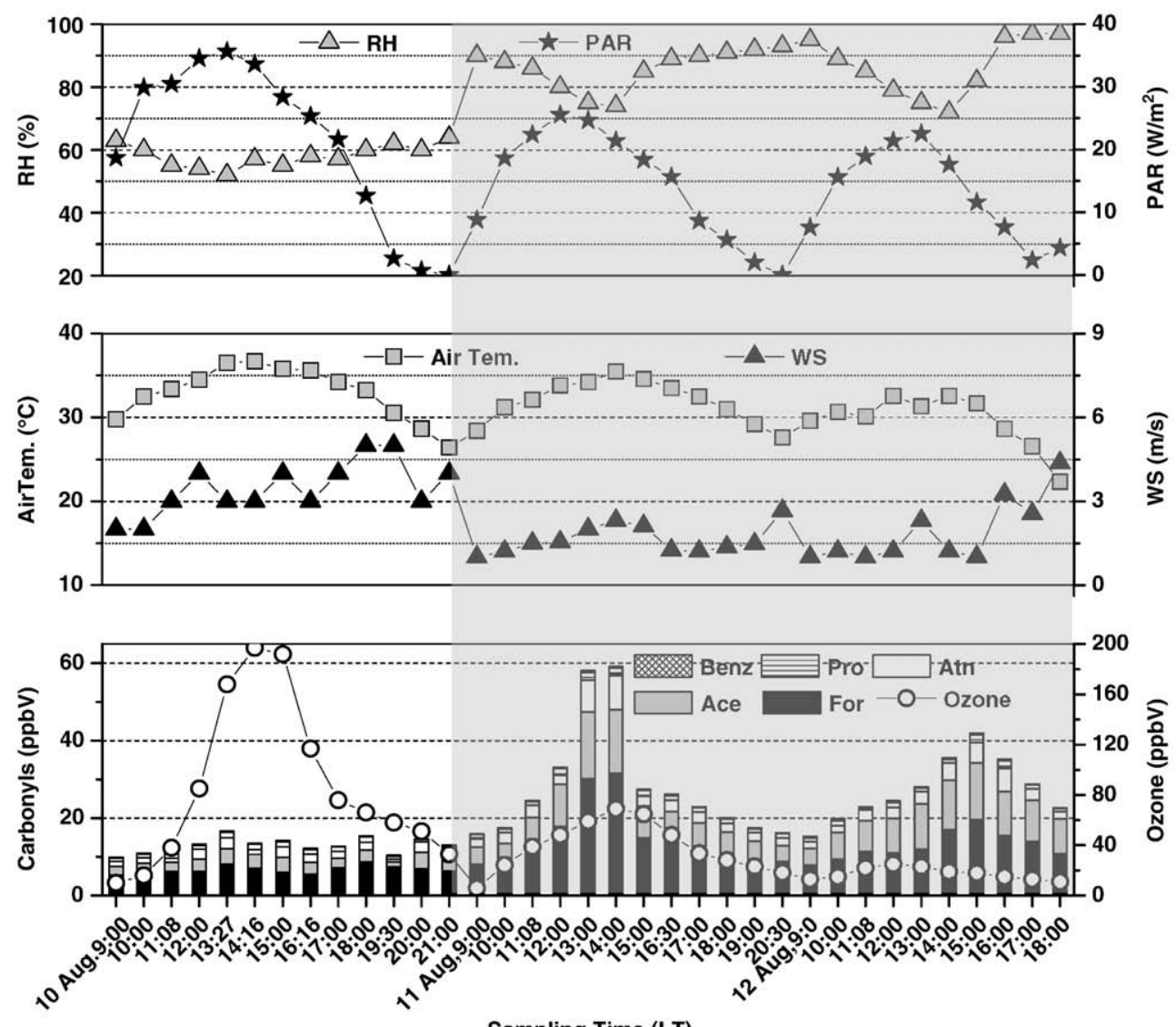

Sampling Time (LT)

Fig. 2. Temporal variations of atmospheric carbonyls and meteorological parameters during the sauna days (August 11-12, 2006). The period of the sauna days is presented as the gray area.

carbonyls could be absorbed on dust particles and removed from the atmosphere by dry precipitation after the dust episode (Guo et al., 2004).

\subsection{Influences of sauna weather on atmospheric carbonyls}

Typical sauna weather was experienced in Beijing on August 11-12, 2006. As Fig. 2 shows, the mixing ratios of atmospheric carbonyls largely increased to $18-60 \mathrm{ppbV}$ on the sauna days from 10 to $17 \mathrm{ppbV}$ on August 10. During the sauna days, the ambient air over Beijing was controlled by a subtropical anticyclone originating from the West Pacific, which contained high content of water vapor (Gao et al., 2005). Under such synoptic conditions, the boundary layer became quite stable and the air pollutants including carbonyls would gradually accumulate. Additionally, as mentioned above, the lower PAR intensities and the lower ozone levels may lead to less degradation of carbonyls and the higher temperatures on the sauna days would result in more carbonyls and their precursors vaporizing from the atmospheric aerosol (Possanzini et al., 2002). The above phenomena would all enhance the levels of carbonyls.

It is worth noting that the diurnal profiles of carbonyls' concentrations on the sauna days displayed their peak at noon, which implied that the atmospheric oxidation also made some contribution to carbonyls (Fig. 2). OH radical is the dominant atmospheric oxidant, which is mainly formed from the photolysis processes of ozone and nitrous acid in polluted atmosphere (Finlayson-Pitts and Pitts, 1997). During the sauna days, OH radicals might mainly be formed from $\mathrm{HONO}$ photolysis (Eq. (1)) other than $\mathrm{O}_{3}$ photolysis due to the lower $\mathrm{O}_{3}$ levels (Fig. 2). $\mathrm{HONO}$ in the daytime can be formed by the heterogeneous reaction of $\mathrm{NO}_{2}$ with $\mathrm{H}_{2} \mathrm{O}$ (Eq. (2)) on wet surfaces, such as aerosol particles and humid ground (Finlayson-Pitts et al., 2003; Su et al., 2008). The high levels of atmospheric aerosol, $\mathrm{NO}_{2}$ and relative humidity on the sauna days could provide favorable conditions to the heterogeneous formation of HONO in the daytime (Hu et al., 2008; Su et al., 2008). High HONO levels in the daytime were observed during the summer haze days in Pear River Delta, China (Su et al., 2008), whose meteorological and environmental conditions were similar to those in Beijing on the sauna days. Therefore, the atmospheric oxidation by $\mathrm{OH}$ radicals from the HONO photolysis might make contribution to carbonyls formation on the sauna days.

$\mathrm{HONO}+h v \rightarrow \mathrm{HO}+\mathrm{NO}$

$\mathrm{NO}_{2}+\mathrm{H}_{2} \mathrm{O}(+$ aerosol $) \rightarrow \mathrm{HONO}+$ other products.

\subsection{Influences of wet precipitation on atmospheric carbonyls}

On the day of August 15, 2005 before it rained, atmospheric carbonyls displayed a typical summer diurnal profile 


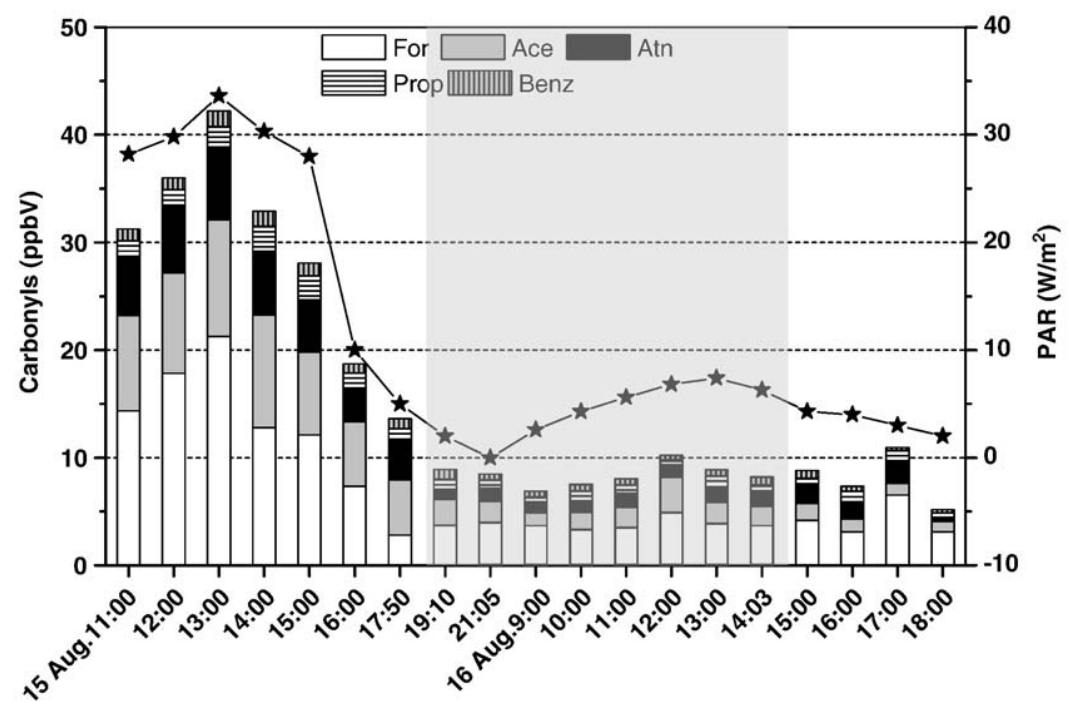

Fig. 3. Temporal variations of atmospheric carbonyls and PAR during a raining event (August 15-16, 2005). The period of raining is presented as the gray area.

with their peak concentrations at noon (13:00 p.m.). During the first hour of rain, the total concentrations of atmospheric carbonyls decreased largely (Fig. 3), which indicated wet precipitation may be an effective removal process for atmospheric carbonyls. Formaldehyde concentration decreased to less than half of that before raining at the first hour of raining while acetaldehyde and acetone began to decrease at the second hour of raining (Fig. 3). Since the Henry's constant of formaldehyde $\left(2.97 \times 10^{3} \mathrm{~mol} \mathrm{~L}^{-1} \mathrm{~Pa}^{-1}\right)$ was higher than those of acetaldehyde and acetone (11.4 and $35.0 \mathrm{~mol} \mathrm{~L}^{-1} \mathrm{~Pa}^{-1}$, respectively), formaldehyde can be more easily removed from the ambient air than acetaldehyde and acetone (Matsumoto et al., 2005). The total concentrations of atmospheric carbonyls decreased significantly at the beginning of rain and kept at fairly constant levels ( 7 ppbV) during the following raining period. This phenomenon may be the combined effect of the rainwater removal and the less photochemical production due to low PAR intensities during the raining days.

In the collected rainwater samples, formaldehyde, acetaldehyde, acetone, propionaldehyde and glyoxal were determined. Their concentrations in those samples were high at the beginning of the rain event and gradually decreased to the relatively low and constant levels, which was similar with the temporal varying patterns of the inorganic ions in rainwater samples (Fig. 4). The chemicals detected in rainwater usually originate from three processes (e.g. existing in $\mathrm{CCN}$, washout from air, and production in the raindrop). The similar temporal varying patterns of the carbonyls and the inorganic ions in the rainwater samples indicated that carbonyls were mainly washed out from the atmosphere into rainwater as the inorganic ions were (Matsunaga et al., 2007).

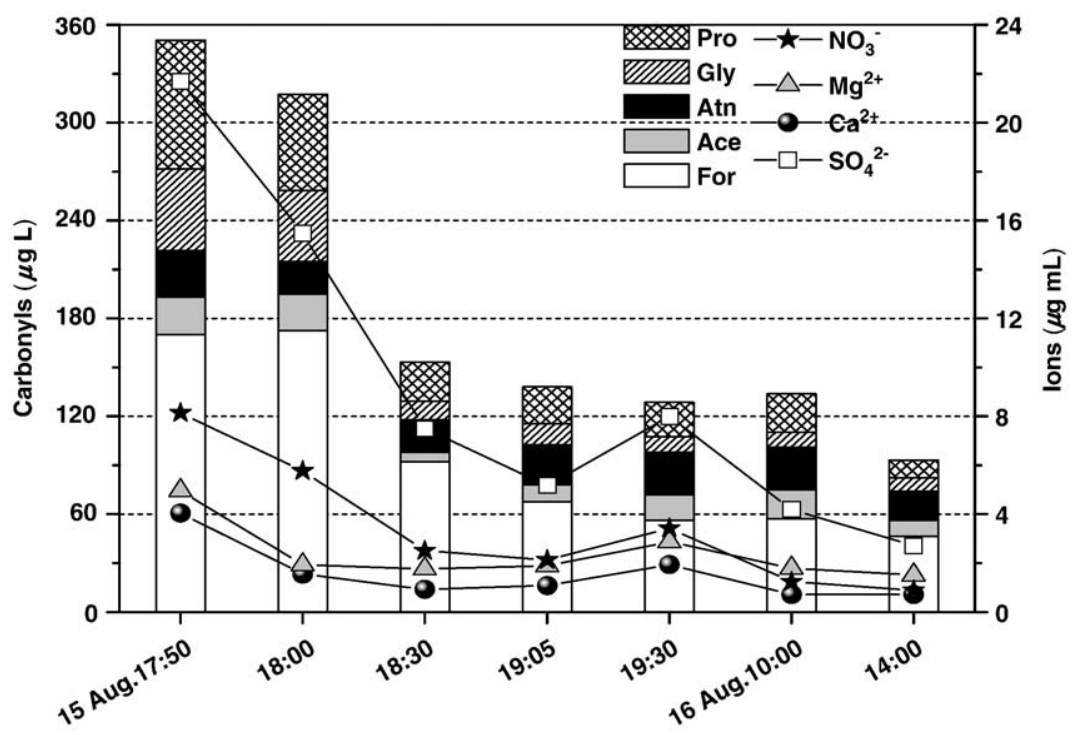

Fig. 4. Temporal variations of carbonyls and inorganic ions $\left(\mathrm{Mg}^{2+}, \mathrm{Ca}^{2+}, \mathrm{SO}_{4}^{2-}, \mathrm{NO}_{3}^{-}\right)$in the rainwater samples during the raining event $($August $15-16,2005)$. 

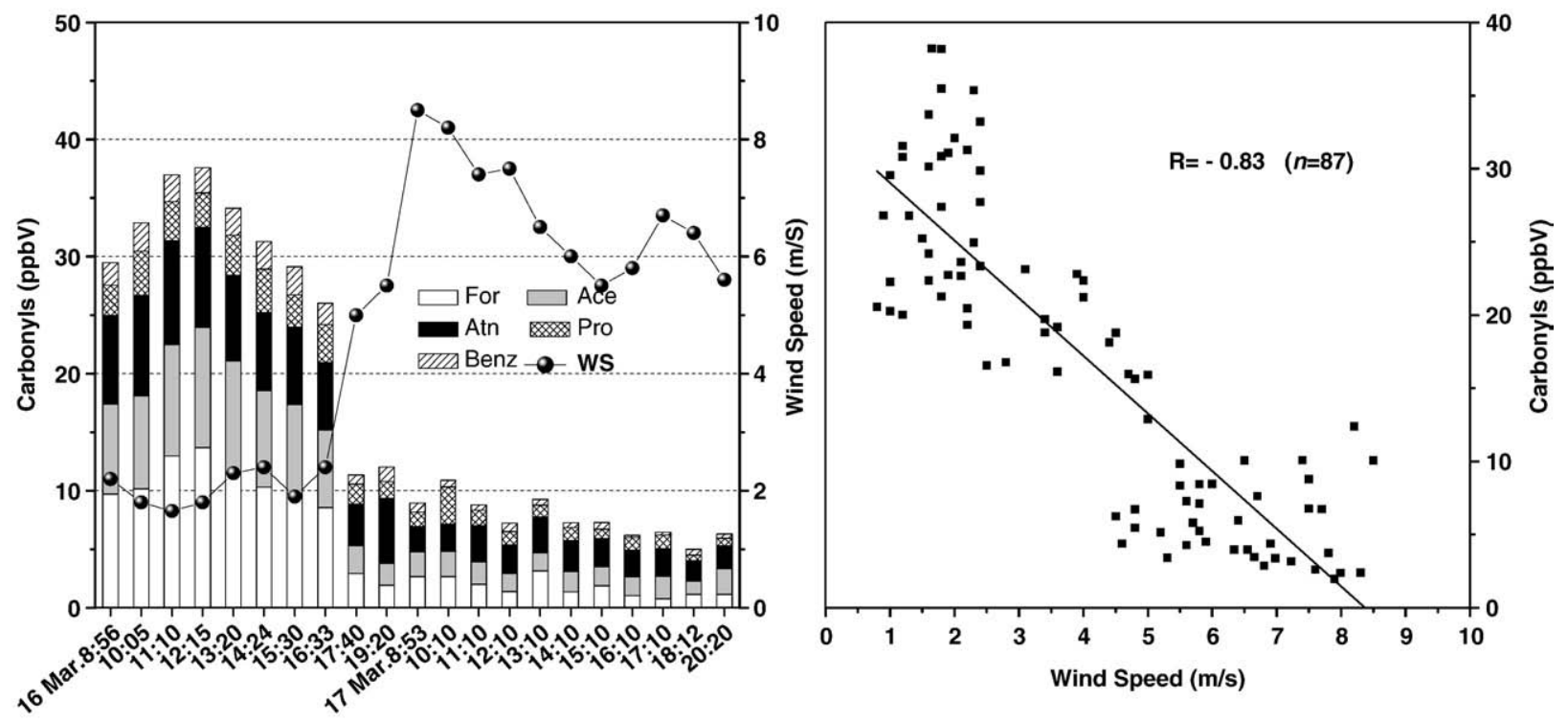

Fig. 5. Influence of wind speed on atmospheric carbonyls during a strong wind event from March 16-17 2005 (left plot) and the correlation between the concentrations of atmospheric carbonyls and wind speeds in March 2005 (right plot).

\subsection{Influence of windy weather on atmospheric carbonyls}

The wind in spring in Beijing is the strongest during the whole year. On the day of March 18, 2005, the boundary layer was quite stable in the daytime, while at 17:40 p.m. wind speed rapidly increased to $6 \mathrm{~m} / \mathrm{s}$. On the next day (March 19), it was still windy and the maximum wind speed reached to more than $9 \mathrm{~m} / \mathrm{s}$. It is well documented that atmospheric pollutants can be quickly diluted by the strong wind. As Fig. 5 shows, the levels of atmospheric carbonyls decreased largely to 5-12 ppbV on March 19 from 28 to 39 ppbV on March 18. A negative correlation was found between the concentrations of atmospheric carbonyls and the wind speeds in spring (Fig. 5). The same relationship was also observed between the concentrations of $\mathrm{SO}_{2}$ and TSP and the wind speeds in Erzurum, Turkey (Sezer et al., 2005). Some studies had revealed that not only wind speeds but also wind directions had significant impacts on air pollutions (Mu et al., 2007; DeGaetano and Doherty, 2004). In this study, wind directions were not found to have evident influences on the levels of carbonyls. In spring in Beijing, the prevailing wind direction is northwest, which is associated with the southward displacement of the Sibirian high pressure. The wind in spring is usually cool, dry and clean, which is conductive to the dispersion of air pollutants.

\section{Conclusions}

In this study, the influences of meteorological conditions on the levels of atmospheric carbonyls were mainly discussed. The stable boundary layer during the dust storm and the sauna days would lead to the accumulation of atmospheric carbonyls. The weaker PAR intensities and the lower levels of ozone in the ambient air during the dust storm and the sauna days would decrease the rates of photolysis and degradation of atmospheric carbonyls and therefore enhance the levels of carbonyls. Wet precipitation was an effective removal process to atmospheric carbonyls and carbonyls might mainly be washed out from the atmosphere into the rainwater. Strong wind could rapidly dilute atmospheric carbonyls and the wind speeds were found to have a negative correlation with the concentrations of atmospheric carbonyls in spring in Beijing.

\section{Acknowledgements}

This research has received financial support from the Chinese National Natural Science Foundation (20807041, 40872212, 40830101, and 20677067), China Postdoctoral Science Foundation (200801270, 20080430861), the National Basic Research Program of China (2005CB422201), the Municipal Science and Technology Foundation of Guizhou Province (2008GZ02725) and Innovation Program of Chinese Academy of Sciences (KZCX2-YW-Q02-03). All authors herein express their deep thanks.

\section{References}

Alves, C.A., 2008. Characterisation of solvent extractable organic constituents in atmospheric particulate matter: an overview. Anais Da Academia Brasileira De Ciencias 80, 21-82.

Anderson, L.G., Lanning, J.A., Barrell, R., Miyagishima, J., Jones, R.H., Wolfe, P., 1996. Sources and sinks of formaldehyde and acetaldehyde: an analysis of Denver's ambient concentration data. Atmospheric Environment 30, 2113-2123.

Andreae, M.O., Crutzen, P.J., 1997. Atmospheric aerosols: biogeochemical sources and role in atmospheric chemistry. Science 276, 1052-1058.

Atkinson, R., 2000. Atmospheric chemistry of VOCs and NOx. Atmospheric Environment 34, 2063-2101.

DeGaetano, A.T., Doherty, O.M., 2004. Temporal, spatial and meteorological variations in hourly $\mathrm{PM}_{2.5}$ concentration extremes in New York City. Atmospheric Environment 38, 1547-1558.

EPA, 1999. Compendium of Methods for the Determination of Toxic Organic Compounds in Ambient Air, EPA Rep. EPA/ 625/R-96/010b, U.S. Environmental. Protect Agency, Cincinnati, Ohio.

Fan, S., Wang, B., Tesche, M., Engelmann, R., Althausen, A., Liu, J., Zhu, W., Fan, Q., Li, M., Ta, N., Song, L., Leong, K., 2008. Meteorological conditions and structures of atmospheric boundary layer in October 2004 over Pearl River Delta area. Atmospheric Environment 42, 6174-6186. 
Finlayson-Pitts, B.J., Pitts, J.N., 1997. Tropospheric air pollution: ozone, airborne toxics, polycyclic aromatic hydrocarbons, and particles. Science 276, 1045-1052.

Finlayson-Pitts, B.J., Wingen, L.M., Sumner, A.L., Syomin, D., Ramazan, K.A., 2003. The heterogeneous hydrolysis of $\mathrm{NO}_{2}$ in laboratory systems and in outdoor and indoor atmospheres: an integrated mechanism. Physical Chemistry Chemical Physics 5, 223-242.

Gao, S.T., Zhou, Y.S., Lei, T., Sun, J.H., 2005. Analysis of weather process and dynamic identification of sauna weather in summer of Beijing. Science in China (Ser. D) 35 (Supple I), 107-114 (In Chinese).

Grosjean, D., Grosjean, E., Moreira, L.F., 2002. Speciated ambient carbonyls in Rio de Janeiro, Brazil. Environmental Science and Technology 36, 1389-1395.

Guo, J., Rahn, K.A., Zhuang, G., 2004. A mechanism for the increase of pollution elements in dust storms in Beijing. Atmospheric Environment $38,855-862$.

Han, T., Lin, J., Wang, Y., et al., 2007. Nature and control of dust storms in the Beijing-Tianjin region, China-a case study of the dust storm in Beijing on April 16. Geological Bulletin of China 26,117-127 (in Chinese).

Hu, M., Wu, Z., Slanina, J., Lin, P., Liu, S., Zeng, L., 2008. Acidic gases, ammonia and water-soluble ions in $\mathrm{PM}_{2.5}$ at a coastal site in the Pearl River Delta, China. Atmospheric Environment 42, 6310-6320.

Jacob, D.J., 2000. Heterogeneous chemistry and tropospheric ozone. Atmospheric Environment 34, 2131-2159.

Matsumoto, K., Kawal, S., Igawa, M., 2005. Dominant factors controlling concentrations of aldehydes in rain, fog, dew water, and in the gas phase. Atmospheric Environment 39, 7321-7329.

Matsunaga, S.N., Guenther, A.B., Izawa, Y., Wiedinmyer, C., Greenberg, J.P., Kawamura, K., 2007. Importance of wet precipitation as a removal and transport process for atmospheric water soluble carbonyls. Atmospheric Environment 41, 790-796.

Mu, Y.J., Pang, X.B., Quan, J.N., Zhang, X.S., 2007. Atmospheric carbonyl compounds in Chinese background area: a remote mountain of the Qinghai-Tibetan Plateau. Journal of Geophysical Research 112, D22302. doi:10.1029/2006JD008211.

Pateraki, S., Maggos, T., Michopoulos, J., Flocas, H.A., Asimakopoulos, D.N., Vasilakos, C., 2008. Ions species size distribution in particulate matter associated with VOCs and meteorological conditions over an urban region. Chemosphere 72, 496-503.

Possanzini, M., Di Palo, V., Cecinato, A., 2002. Sources and photodecompositon of formaldehyde and acetaldehyde in Rome ambient air. Atmospheric Environment 36, 3195-3201.

Pudasainee, D., Sapkota, B., Shrestha, M.L., Kaga, A., Kondo, A., Inoue, Y., 2006. Ground level ozone concentrations and its association with NOx and meteorological parameters in Kathmandu valley, Nepal. Atmospheric Environment 40, 8081-8087.

Sachez-Ccoyllo, O., Ynoue, R.Y., Martins, L.D., de Fatima Andrade, M., 2006. Impacts of ozone precursor limitation and meteorological variables on ozone concentration in Sao Paulo, Brazil. Atmospheric Environment 40, $552-562$.

Salisbury, G., Williams, J., Gros, V., Bartenbach, S., Xu, X., Fischer, H., Kormann, R., de Reus, M., Zollner, M., 2006. Assessing the effect of a Saharan dust storm on oxygenated organic compounds at Izana, Tenerife (July-August 2002). Journal of Geophysical Research 111, D22303. doi:10.1029/2005JD006840.

Seto, S., Hara, H., 2006. Precipitation chemistry in western Japan: its relationship to meteorological parameters. Atmospheric Environment $40,1538-1549$.

Sezer, T.F., Nuhoglu, A., Bayraktar, H., 2005. Impacts of some meteorological parameters on $\mathrm{SO}_{2}$ and TSP concentrations in Erzurum, Turkey. Chemosphere 59, 1633-1642.

Silva, P.J., Vawdrey, E.L., Corbett, M., Erupe, M., 2007. Fine particle concentrations and composition during wintertime inversions in Logan, Utah, USA. Atmospheric Environment 41, 5410-5422.

Su, H., Cheng, Y.F., Cheng, P., Zhang, Y.H., Dong, S., Zeng, L.M., Wang, X., Slanina, J., Shao, M., Wiedensohler, A., 2008. Observation of nighttime nitrous acid (HONO) formation at a non-urban site during PRIDEPRD2004 in China. Atmospheric Environment 42, 6219-6232.

Sun, J., Zhao, L., Zhao, S., 2007. Numerical simulation on a dust storm producing strong deposition over North China in the spring of 2006. Climatic and Environmental Research 12, 339-349 (in Chinese).

Thomas, E.R., Frost, G.J., Rudich, Y, 2001. Reactive uptake of ozone by proxies for organic aerosols: surface-bound and gas phase products. Journal of Geophysical Research 106 (D3), 3045-3056.

Wang, G., Kawamura, K., Lee, M., 2009. Comparison of organic compositions in dust storm and normal aerosol samples collected at Gosan, Jeju Island, during spring 2005. Atmospheric Environment 43, 219-227.

Xie, S., Yu, T., Zhang, Y., Zeng, L., Qi, L., Tang, X., 2005. Characteristics of $\mathrm{PM}_{10}$, $\mathrm{SO}_{2}, \mathrm{NOx}$ and $\mathrm{O}_{3}$ in ambient air during the dust storm period in Beijing. Science of the Total Environment 345, 153-164.

Zhang, B.N., Kim Oanh, N.T., 2002. Photochemical smog pollution in the Bangkok Metropolitan Region of Thailand in relation to $\mathrm{O}_{3}$ precursor concentrations and meteorological conditions. Atmospheric Environment 36, 4211-4222.

Zhou, X.L., Mopper, K., 1993. Carbonyl compounds in the lower marine troposphere over the Caribbean Sea and Bahamas. Journal of Geophysical Research 98, 2385-2392. 